Supporting Information for:

\title{
Continuous Low Voltage DC Electroporation on a Microfluidic Chip with Polyelectrolytic Salt Bridges
}

Sang Kyung Kim ${ }^{\dagger}$, Jae Hyun $\mathrm{Kim}^{\dagger}$, Kwang Pyo Kim ${ }^{\ddagger}$ and Taek Dong Chung ${ }^{\S *}$

${ }^{\dagger}$ Nanobio Research Center, Korea Institute of Science and Technology, Seoul 130-650,

Korea, ${ }^{\ddagger}$ Department of Molecular Biotechnology, Institute of Biomedical Science and

Technology, Konkuk University, Seoul, 143-701, Korea, and ${ }^{\S}$ School of Chemistry,

Seoul National University, Seoul 151-747, Korea

AUTHOR'S E-MAIL ADDRESSES: Sang Kyung Kim: sangk@kist.re.kr, Jae Hyun Kim: jae0221@kist.re.kr , Kwang Pyo Kim: kpkim@konkuk.ac.kr, Taek Dong Chung: tdchung@snu.ac.kr

${ }^{\S}$ Tel: +82-2-880-4362, Fax: +82-2-887-4354, E-mail: tdchung@snu.ac.kr 
Experimental setup for impedance analysis: The microchip with a pDADMAC plug in the middle of a straight microchannel $(5 \mathrm{~cm} \times 1 \mathrm{~mm} \times 0.5 \mathrm{~mm})$ was placed in a faraday cage to reduce environmental noise. The channel was filled with $3 \mathrm{M} \mathrm{KCl}$ solution and the conductivity of the plug was measured with $\mathrm{Pt}$ or $\mathrm{Ag} / \mathrm{AgCl}$ electrodes (made of chlorinated $\mathrm{Ag}$ wire, and its formal potential was $0.2 \mathrm{~V}$ (vs. $\mathrm{Ag} / \mathrm{AgCl})$ ) in both ends of the microchannel.

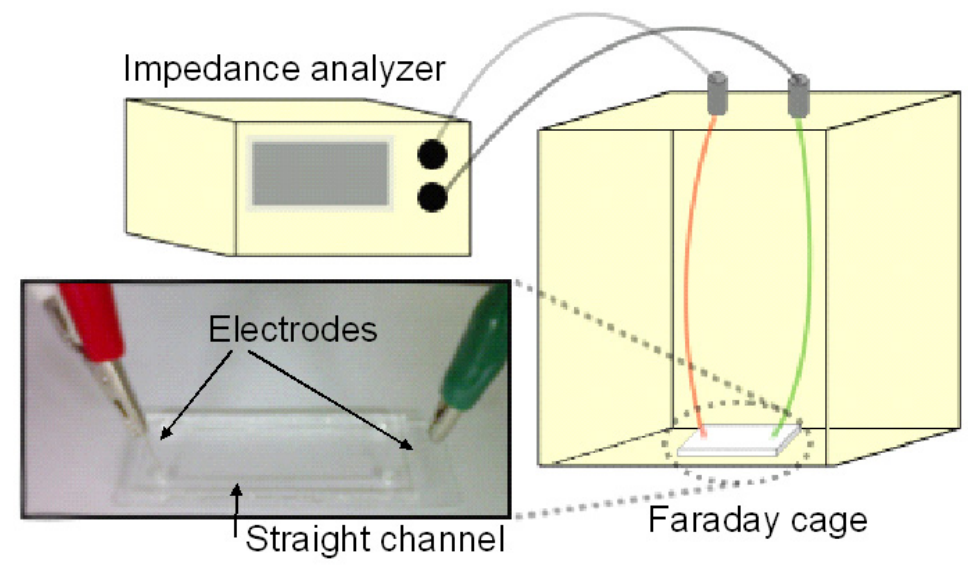

Figure 1. Setup for the impedance analysis of pDADMAC hydrogel, hypertonic solution and media.

Procedure of electroporation: $\mathrm{Two} \mathrm{Ag} / \mathrm{AgCl}$ wire electrodes were placed in two reservoirs, respectively, which are filled with the hypertonic solution (aqueous $3 \mathrm{M} \mathrm{KCl}$ ) on the chip. DC bias ranging from 5 to $20 \mathrm{~V}$ was applied between the electrodes with a power supply (E3631A, Agilent technologies, USA). Cells were delivered into the microchannel from a syringe pump (VITFIT, Lambda, USA) through Teflon tubing (I.D. $0.3 \mathrm{~mm}$ ). Volume flow rate ranged from 
1.6 to $8.5 \mu \mathrm{L} \min ^{-1}$ during the experiments. Every electroporation typically took $1 \sim 2 \mathrm{~min}$ and the treated cells were collected in the outlet reservoir for inspection. The excitation light was optically filtered by a $530 \pm 20 \mathrm{~nm}$ band-pass filter and the transported propidium iodide (PI) was identified by measuring the emission at $590 \mathrm{~nm}$ in a fluorescence microscope LSM 5 Pascal (Carl Zeiss, Germany). The cells in the outlet reservoir were classified as live-permeated, nonpermeated and dead cells and counted by a hematocytometer.

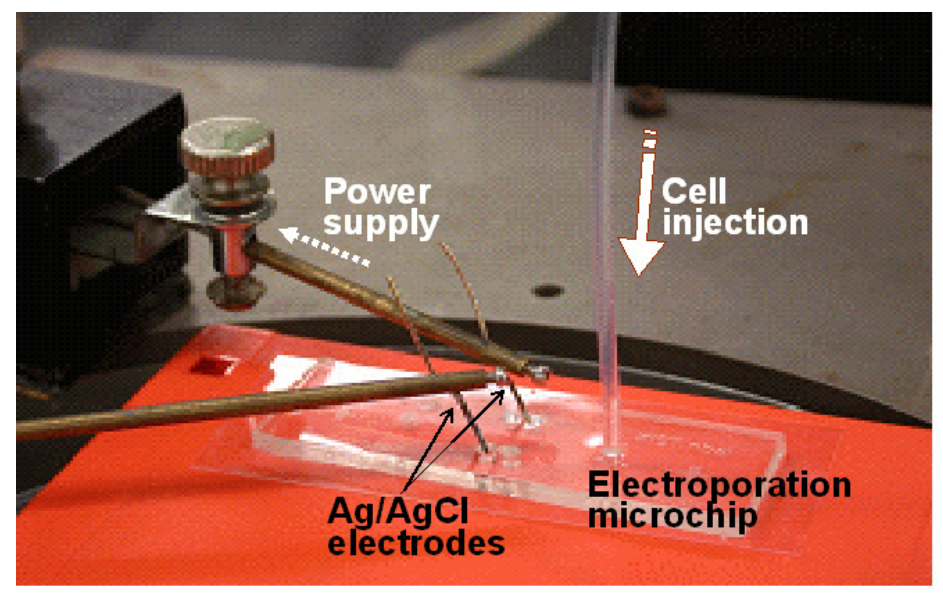

Figure 2. Experimental set up for cell electroporation

Characterization of the salt bridge plugs: Table 1 shows that the ionic conductivity is about $16 \mathrm{~S} \mathrm{~m}^{-1}$ with the crosslinker content from 2 to $10 \%$. The pDADMAC plugs and the hypertonic solutions showed similar conductivity but media solution was 10 times more resistive. When those materials constructed a pathway for ionic flux as in Figure 1, major portion of applied 
potential gradient could be concentrated in the microchannel where cells flowed.

Table 1 Swelling and ionic conductivity of pDADMAC plugs with different content of crosslinker and other solutions.

\begin{tabular}{|l|c|c|}
\hline Material & $\begin{array}{c}\text { Conductivity } \\
(\mathrm{S} / \mathrm{m})\end{array}$ & $\begin{array}{c}\text { Swelling ratio } \\
(\%)\end{array}$ \\
\hline $\begin{array}{l}\text { Hydrogel } \\
(\text { crosslinker } \%)\end{array}$ & 17.6 & $59 \pm 4$ \\
\hline $\begin{array}{l}\text { Hydrogel } \\
\text { (crosslinker 5\%) }\end{array}$ & 15.6 & $44 \pm 7$ \\
\hline $\begin{array}{l}\text { Hydrogel } \\
\text { (crosslinker 10\%) }\end{array}$ & 16.4 & $25 \pm 10$ \\
\hline $3 \mathrm{M} \mathrm{KCl}$ & 28.1 & N/A \\
\hline Media & 1.6 & N/A \\
\hline
\end{tabular}

Swelling was measured by comparing lengths of pDADMAC plugs before and after soaking in de-ionized water. Higher concentration of crosslinker resulted in lower swelling ratio of the hydrogel. However, the crosslinker readily precipitates in $10 \%$ solution due to its low solubility. 